\title{
Rutaceae nova da Amazônia
}

\author{
Byron W. P. de Albuquerque (*) \\ IVÍ́RIO HONDA (*) \\ Instituto Nacional de Pesquisas \\ da Amazônia
}

\begin{abstract}
SINOPSE
Os autores acrescentam no presente trabalho a diagnose e a descrição microscópica da madeira da especie nova Fagara Machadoi Albuq., completandose a nota prévia anteriormente publicada (Albuquerque \& Honda, 1971).
\end{abstract}

\section{MATERIAL E MÉTODOS}

Da amostra da madeira coletada e registrada na Xiloteca do INPA sob o numero X-417\%. foram feitos os cortes histológicos (transver. sal, radial e tangencial), que depois de preparadas de acordo com as técnicas usuais, foram montados em lâminas histológicas recebeildo o número 702 em nosso laminário.

Os termos usados estão de acordo com c Glossário de Termos usados em Anatomia de Madeiras (Milanez \& Bastos, 1960) e as grandezas, com as propostas por Chattaway (1932), com as modificações adotadas pelo Instituto de Pesquisas Tecnológicas — S. Paulo (Mainieri, 1962). A classificação dos raios é baseada na de Kribs (Metcalfe \& Chalk, 1965).

Para a dissociação dos elementos fibrosos usamos solução de $\mathrm{HNO}_{3}$ a $50 \%$.

O estudo macroscópico foi feito através da lupa $10 \mathrm{X}$ e microscópio estereoscópico trinocular Olympus, modelo $\mathrm{X}$.

Os caracteres microscópicos foram observados em Projetor Universal UP-360 T II. Olympus e microscópio binocular E. Leitz.

A fotomacrografia foi feita pelo Setor de Fotografia do INPA e as fotomicrografias são de nossa autoria, obtidas em microscópio trinocular Olympus modelo FHFTR-3.
DLAGNOSE DA NOVA ESPÉCIE

?.t.

Fagara Machadoi Albuq., n. sp., Fig. 1

Arbor $30 \mathrm{~m}$ alta, diam. ca. $45 \mathrm{~cm}$. Caule ramoso, teretibus, aculeis valde paucis munito; ramis brunneis, dense aculeis munitis, teretibus, longitudinaliter rugosis, pilosis. Foliis alternis, paripinnatis, pilosis, ad $74,5 \mathrm{~cm}$ longis, 3-10 paribus foliolorum; petiolis teretibus, velutinis, aculeis munitis, longitudinaliter rugosis, basi valde dilatata, ad $59 \mathrm{~cm}$ iongis; foliolis magnis, oblongo ellipticis, alternis vel oppositis, coriaceis, leviter crenulatis supra glabriusculis, subtus velutinis atque virido-luteolis, pellucidopunctatis, petiolulatis, inferis minoribus, ca. $7-19,5 \mathrm{~cm}$ longis, $3,5-8 \mathrm{~cm}$ latis, apice acuminatis, acumen breve, basi inaequalia, acuta vel subobtusa vel obtusa vel subrotundata; nervo medio utrimque prominente, interdum aculeis munitis, leviter et longitudinaliter rugoso; nervis lateralibus utrimque prominulis, interdum supra initialiter prominulis, deinde ad foliolis margine immersibus sulcum formans, brochidodromatibus, interdum camptodromatibus; petiolulis subteretibus, velutinis, basi articulatis, ca. $10 \mathrm{~mm}$ longis.

Inflorescentia feminea panniculata, fructifera; panniculis parvis, terminalibus; ramificationibus subquadrangularibus, articulatis, suberoso-rugosis, leviter pilosis, bracteolis triangularibus, acutis, basi lata munitis, ca. $1 \mathrm{~mm}$ longis; pedicellis ca. $4 \mathrm{~mm}$ longis. Fructus 1-3 coccis, parvis, conchiformibus, subglobosis, bivalvis facie aspera, glandulosis, leviter pilosis. ca. $7-8 \mathrm{~mm}$ longis, $6-7 \mathrm{~mm}$ latis; endocarpio sicco, libero duobus partibus subdiviso, aspero; semen 1. subglobosa, leviter carinata, extus nigra, pernitida, laevis.

(*) - Bolsista do Conselho Nacional de Pesquisas. 


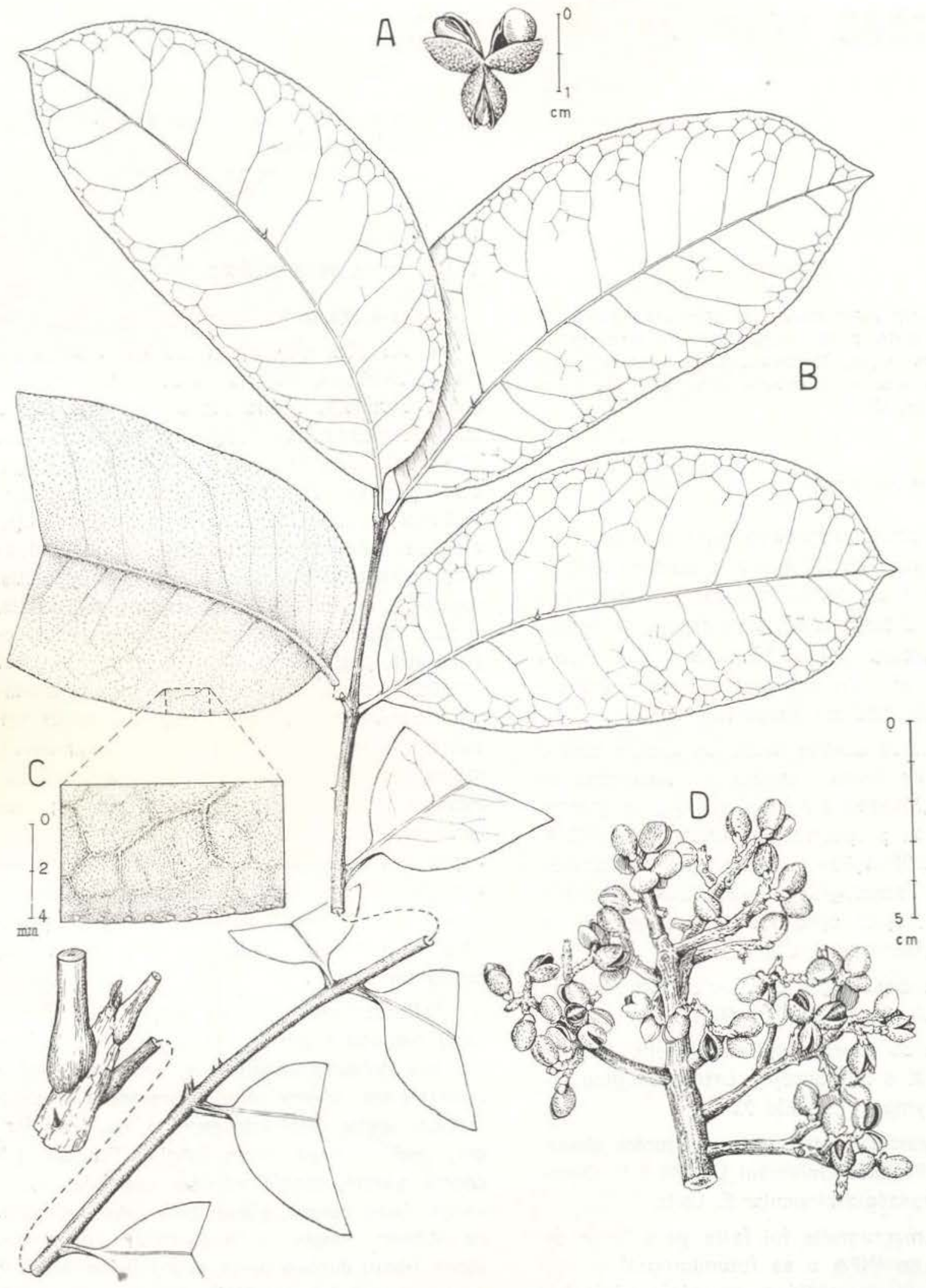

Fig. $1-A$, Frutos (cocas) $-2 \mathrm{X} ; \quad B$, Folha composta - tamanho natural; $C$, Detalhe da área delimitada em um dos folíolos da figura $\mathrm{B}$, mostrando o aspecto velutino - $5 \mathrm{X} ; \mathrm{D}$, Ramo frutífero - tamanho natural. (Desenhos de J. Dellome) 
Árvore de $30 \mathrm{~m}$ de altura, $45 \mathrm{~cm}$ de diâmetro. Tronco cilindrico, ramificado, munido de muito poucos acúleos; ramos acastanhados, densamente munidos de acúleos, cilíndricos, longitudinalmente rugosos, pilosos. Folhas alternas, paripinadas, pilosas, até $74,5 \mathrm{~cm}$ de comprimento, com 3-10 pares de folíolos; pecíolos cilíndricos, velutinos, munidos de acúleos, lon. gitudinalmente rugosos, de base muito dilatada, até $59 \mathrm{~cm}$ de comprimento; folíolos grandes, oblongo-elípticos, alternos ou opostos, coriáceos, levemente crenulados, glabriúsculos na face superior, velutinos e verde-amarelados na face inferior, pelúcido-pontuados, peciolulados, os inferiores menores, cerca de $7-19,5 \mathrm{~cm}$ de comprimento e $3,5-8 \mathrm{~cm}$ de largura, ápice acuminado, acúmen curto, base inequilátera, aguda cu subotusa ou obtusa ou subarredondada; nervura central proeminente em ambas as faces, às vezes munida de acúleos, levemente rugosa no sentido longitudinal; nervuras laterais promínulas em ambas às páginas, às vezes na face su. perior inicialmente promínulas, depois submersas em direção à margem dos foliolos formando um sulco, broquidódroma, às vezes camptódromas; peciólulos subcilíndricos, velutinos, articulados na base, cerca de $10 \mathrm{~mm}$ de comprimento. Inflorescência feminina frutífera, em paniculas pequenas, terminais; ramificações subquadrangulares, articuladas, suberoso-rugosas, curtamente pilosas, munidas de bactéólas triangular-agudas, de base larga, cerca de $1 \mathrm{~mm}$ de comprimento pedicelos cerca de $4 \mathrm{~mm}$ de comprimento. Fruto 1-3 cocas pequenas, conchiformes, subglobosas, de superfície áspera, glaudulosas, curtamente pilosas, cerca de

\section{DIÂMETRO DOS POROS}

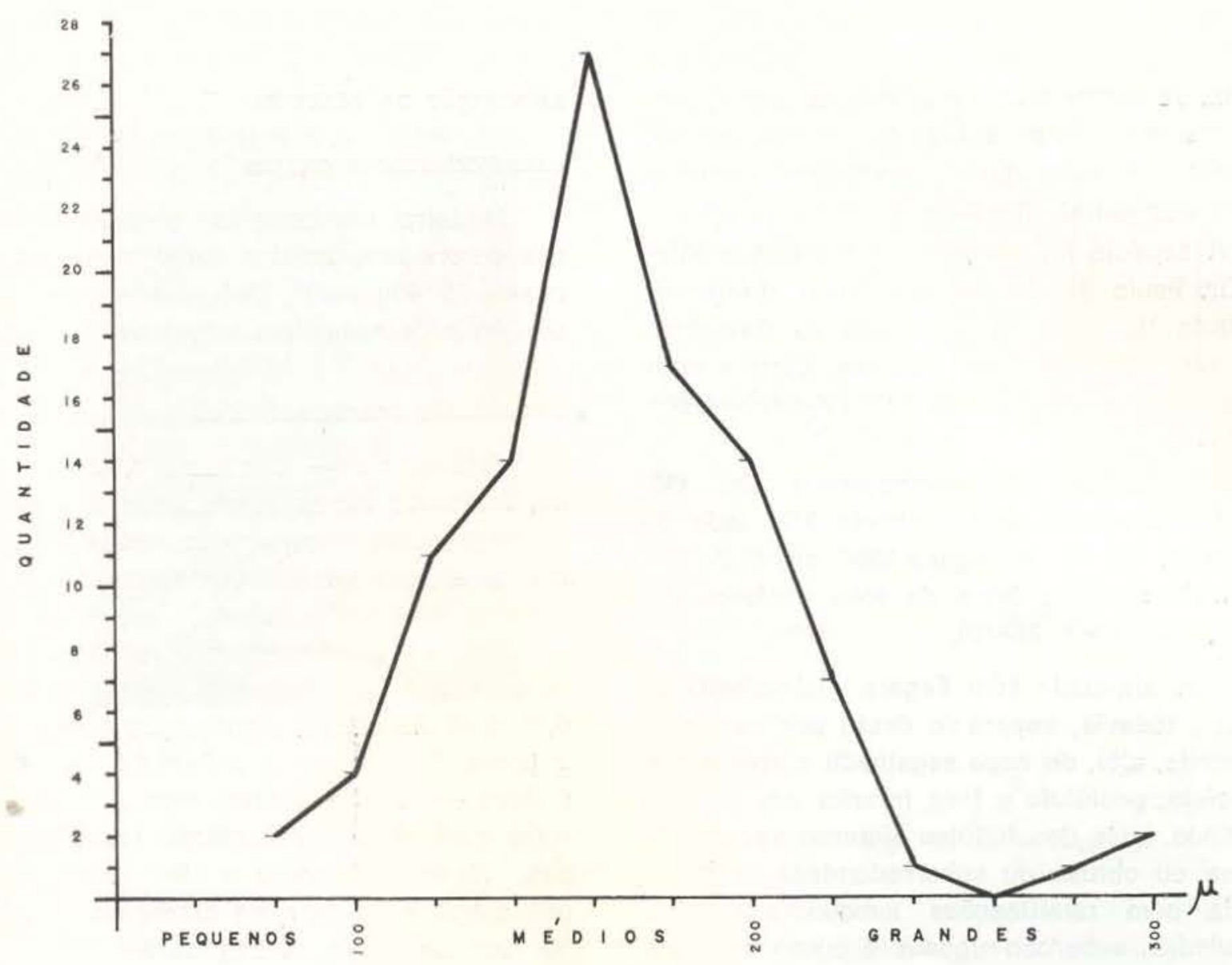




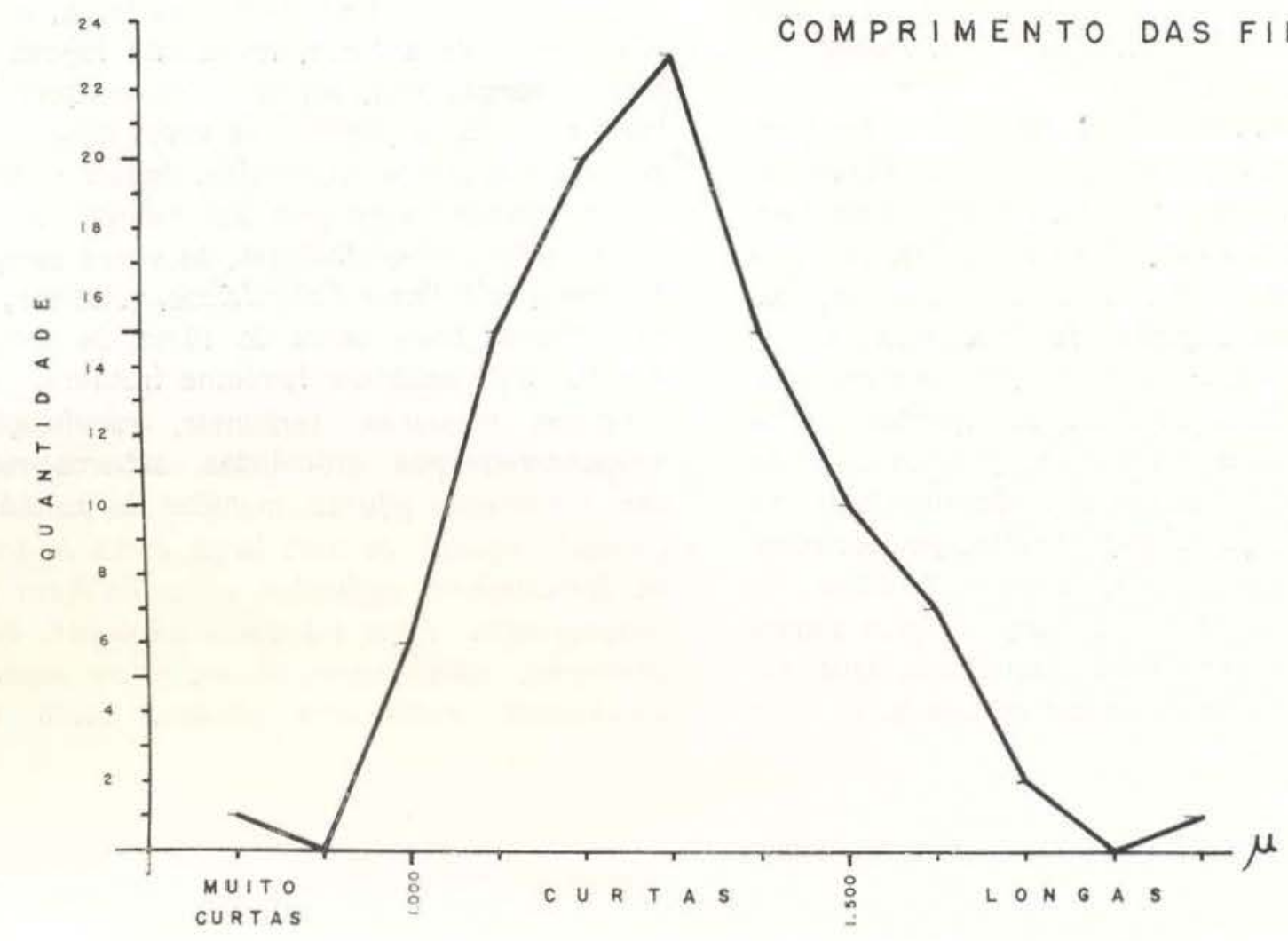

$7-8 \mathrm{~mm}$ de comprimento e $6-7 \mathrm{~mm}$ de largura; en docarpo seco, solto, subdividido em 2, áspero; semente 1, subglobosa, levemente carinada, casca negra, lisa, muito nítida.

A espécie foi denominada em homenagem ao Dr. Paulo de Almeida Machado, diretor do instituto Nacional de Pesquisas da Amazônia, que vem norteando com rara sabedoria e competência a pesquisa cientifica na Amazônia Brasileira.

Typus - Estrada Manaus-Itacoatiara, km 155. no varadouro para a picada XIX., lado direito, leg. W. Rodrigues 9000, em 11-2-1971, mata de terra firme de solo argiloso $(\mathrm{Ho}$. lotypus INPA 28470).

Tem afinidade com Fagara djalma-batistae Albuq., todavia, separa-se desta por ser árvore grande, alta, de copa esgalhada e apresentar o pecíolo, peciólulo e face inferior dos foliolos velutinos, base dos foliolos algumas vezes subobtusa ou obtusa ou subarredondada, inflorescência com ramificações subquadranguiares, articuladas, suberoso-rugosas e cocas maiores.

DESCRIÇÃO DA MADEIRA

\section{CARACTERÍSTICAS GERAIS}

Madeira branco-palha e sedoso-brilhante nos cortes tangencial e radial; moderadamente pesada $\left(0,60 \mathrm{~g} / \mathrm{cm}^{3}\right)$. Grä direita, textura mé. dia, insípida e inodora. Fácil de trabalhar.

\section{CARACTERES MACROSCÓPICOS}

Parênquima - Contrastado, visivel a olho nu, formando faixas contínuas e interrompidas e irregularmente espaçadas; raramente aliforme e aparentemente vasicêntrico. Poros Visíveis a olho desarmado, vazios, solitários predominantes, geminados e multiplos de $3 \mathrm{e}$ raramente de 4 . Pequenos a médios $(0,1 \mathrm{~mm}$ a $0,3 \mathrm{~mm}$ de diâmetro); distribuição difusa; poucos a pouco numerosos $\left(3\right.$ a $\left.7 / \mathrm{mm}^{2}\right)$. Linhas vas culares - Visíveis mesmo sem lente em linhas retas $\mathrm{e}$ às vezes apresentando leves sinuosida. des. Raios - Visíveis a olho nu os mais largos e sob lente os mais estreitos; numerosos. $\mathrm{Na}$ face radial, pouco contrastado com o fundo 


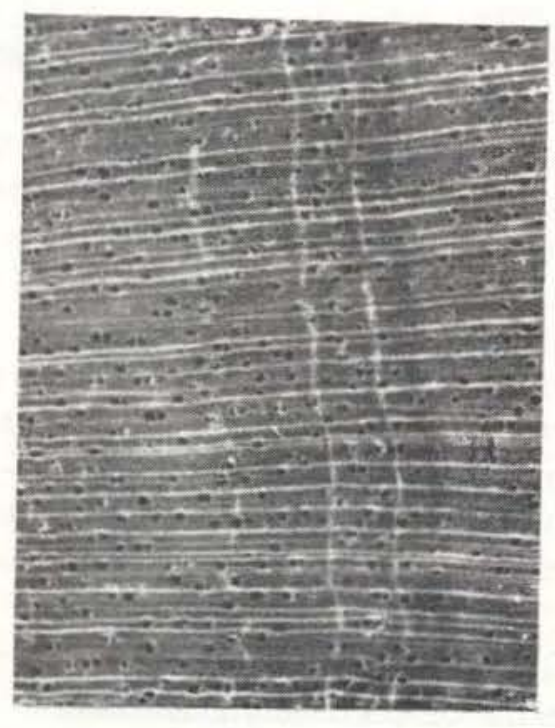

1

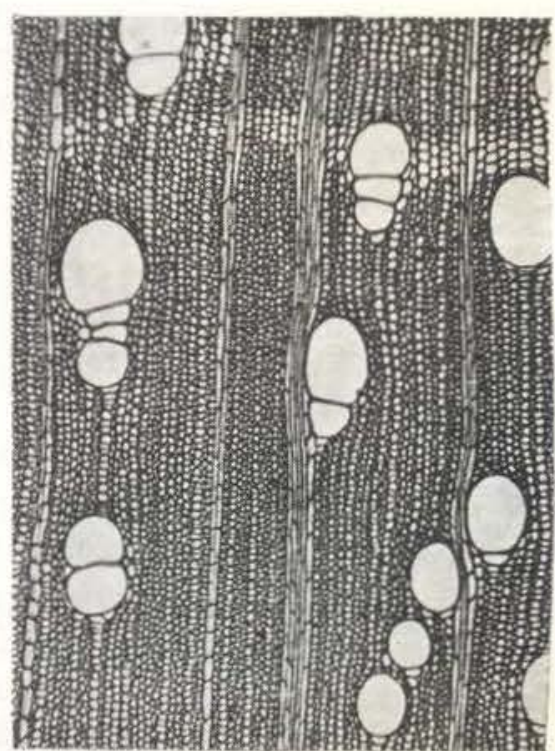

2

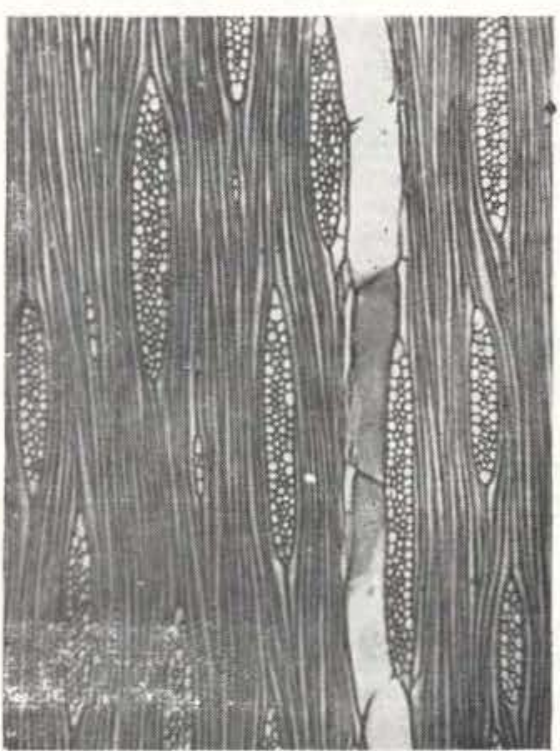

3

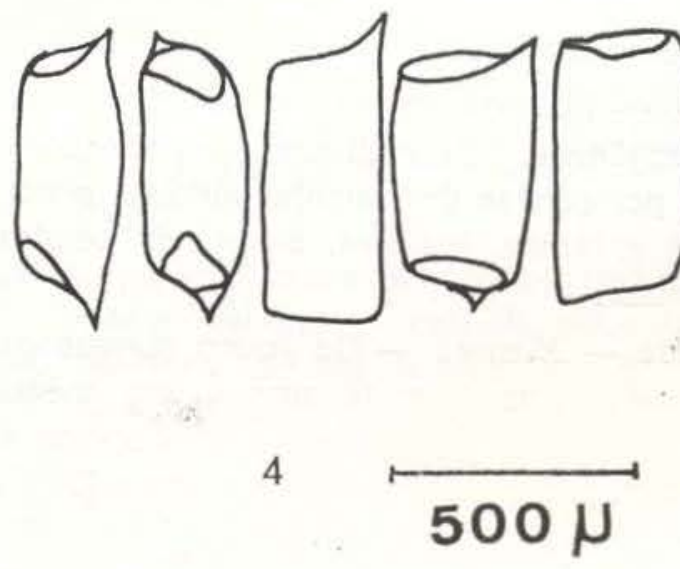

Fig. $2-1$ ) Aspecto macroscópico - 10X; 2) Corte transversal $-50 \mathrm{X}$; 3) Corte tangencial $-50 \mathrm{X}$ 4) Elementos vasculares. 
sedoso, porém visıveis a olho nu. $\mathrm{Na}$ superfície tangencial, apenas notados a olho desarmado, irregularmente dispostos. Canais secretores e máculas medulares - Não foram observados. Camadas de crescimento - Aparentemente demarcadas por faixas do parênquima terminal e zonas fibrosas mais escuras.

\section{CARACTERES MICROSCÓPICOS}

Poros:

De pequenos a médios, com predominância destes $(83 \%)$. De poucos a pouco numerosos. Solitários, geminados e múltiplos de 3-4; raríssimas cadeias radiais de até 6 poros e irregulares. Número - De 4 a $13 / \mathrm{mm}^{2}$, com predominância dos solitários e geminados $444 \%$ e $37 \%$, respectivamente). Diâmetro - de 80 a $290 \mathrm{mi}$. cra, mais comumente entre 120 e 200 micra e em média 160 micra. De pequenos a grandes com predominância dos médios $(90 \%$ ! Elementos vasculares - De curtos a longos, com predominância daqueles (52\%); de 300 a $680 \mathrm{mi}-$ cra e em média 507 micra. Pontuações intervasculares - Pares de pontuaçöes areoladas, de disposição alterna e contorno poligonal; de 5 a 7 micra, abertura inclusa às vezes coalescentes (2-5 pontuações). Placas de perfuração - Simples.

\section{Parênquima radial :}

Tipo - Homogếneo II de Kribs e fracamente heterogèneos. Os multisseriados são constituídos por células de tamanho variável, sendo as mais externas, maiores, simulando células envolventes.

Raios - Número - De pouco numerosos a numerosos com 5 a $10 / \mathrm{mm}^{2}$ e em média $7 / \mathrm{mm}^{2}$. Altura - De extremamente baixos a baixos com predominância dos primeiros $(57 \%)$ e de 70 a 1.040 micra com a média de 451 micra e de 2 a 56 células. Largura - De 1 a 5 células, maioria de $4(43 \%)$ e $1(25 \%)$. Células apicais - De 1 a 2 células, às vezes ausentes em um dos extremos do raio ou em ambos (raramente)?

\section{Parênquima axial :}

Tipo - Paratraqueal escasso, reduzido a algumas células vizinhas aos poros e apotraqueal formando faixas com largura de 1 a 4 células, raramente 5. Série - De 3 a 8 células.

\section{Fibras :}

Tipo - Libriformes, homogêneas. Comprimento - De 760 a 1.840 micra, mais freqüentemente entre 1.100 a 1.500 micra e em média 1.226 micra. De muito curtas a longas, com predominância das curtas $(79 \%)$. Diâmetro - De 18 a 34 micra, com a média de 24 micra.

Parede - Fina, de 3 a 5 micra e em média 4 micra. Lume - Largo, de 12 a 24 micra, e em média 18 micra. Pontuaçôes - Simples, observadas somente nas paredes radiais.

Canais intercelulares - Presentes, embora raros.

Camadas de crescimento - Delimitadas por faixas de parênquima terminal inicial e por zonas fibrosas cujas células apresentam paredes mais espessas.

$$
\text { Máculas medulares - Não foram observa- }
$$
das.

\section{SUMMARY}

In this paper the diagnosis and wood microscopic description of the new species Fagara Machadoi Albuq are added by the authors, completing a previous note published before.

Results are documented by botanical description of the species, by general characteristics and macroscopic and microscopic descriptions of its wood, and by figures.

\section{BIBLIOGRAFIA CITADA}

Albuquerque, B. W. P. de \& Honda, M.

1971 - Nota prévia sôbre Rutaceae nova da Amazônia. Acta Amazonica, Manaus, 1 (1): 24.

Chattaway, M. M.

1932 - Proposed Standard for numerical values used in describing woods. Trop. Woods, New Haven, $29: 20-28$.

MAINIERI, C.

1962 - Madeiras leves da Amazônia empregadas em caixotaria; estudo anatômico macro e microscópico. Publ. Inst. Pesq. Tec., São Paulo, $686: 39$.

Metcalfe, C. R. \& Chalk, L.

1965 - Anatomy of the Dicotyledons. Oxford, Clarendon Press. v. 1: est. C.

MiLANez, F. R. \& Bastos, A. DE M.

1960 - Glossário dos têrmos usados em anatomia de madeiras. Rio de Janeiro, Irm. Di Giorgio \& Cia. Ltda. p.: 19-20. 